\title{
Resistance Calculation and Performance Simulation about 2000 HP Libin Zhou ${ }^{1, a}$, Huanguo Chen ${ }^{2, b}$ \\ ${ }^{1}$ School of Mechanical and Power Engineering,Dalian Ocean University,Dalian,116023,China \\ ${ }^{2}$ Dalian Liaonan Shipyard, Dalian,116041, China. \\ aemail: zlb@dlou.edu.cn, bemail:zlbchg@163.com
}

Keywords: 2000 HP; Tribon software; Resistance calculation; Simulation

\begin{abstract}
The methord of underwater shield string is put forward in 2000 HP.The quantitative design and calculation are finished with no clear specification requirement and calculation method. By the calculation and analysis of the viscous resistance of the wet surface,it shows that the methord can not only satisfy the use requirement, but also make the center of gravity, ship sailing resistance and speed satisfy the requirements of expectations.
\end{abstract}

\section{Introduction}

In recent years,with China's continous and rapid economic development,the coastal cargo throughput also has increased substantially.And the operation of the ship in the port is also more and more containerized.[1].According to eleventh in compendium of 5 years of programs in Dalian Port group and the "Dalian Port overall planning" requirements, Dalian Port group company will consider "an island and three gulf" as the core, and develop Changxing Island and nearby Industrial Zone [2].Because the influence of wind power and water power is great, the maneuve $r$ ability is limited.In this condision it often happens collision or contact accidents.In order to ensure the safety of large ships,it often needs the tug's help [3-4]. 2000HP is strictly restricted by the weight of the rubber fender.So we ought to design the fender to meet the requirements and the stability of the ship.Also the design should reach the resistance and the speed of the ship.For example there is a ship which captain is $28.5 \mathrm{~m}$. Its principal dimensions is small,but the load is larger.So the total weight of the rubber fender is strictly limited within 25t.In order to ensure that the ship has enough margin,the rubber fender needs to cover a lot of places.Thus how to control the weight of the r rubber fender to meet the whole performance has become the focus of the design.

\section{Design and calculation of the fender under the water}

Towing under the water is an important difference from the other tugs.So we must have full consideration of the main dimension and the shape feature .By software Tribon,we simulates the operation condition of the towing tug and calculates the weight of the fender.It assumes that the tug isn't impacted by the wind and wave,so the swing angle also is not too large. We calculate by taking the maximum rolling angle $\theta \mathrm{m}=8^{\circ}$ and the maximum pushing angle $\Phi \mathrm{m}=1^{\mathrm{o}}$ as an example.

The approximate calculation formula of the rolling intertia moment in still water is [5]:

$$
I_{x x}=\frac{D}{12 g}\left(B^{2}+4 Z_{g}^{2}\right)
$$

In the formula: $D-$ Ship displacement;

$g$ - The acceleration of gravity;

B-—Molded breadth ;

$\mathrm{Z}_{g}$ - - The altitude of the center of gravity from baseline.

Roll inertia moment is: $J_{x x}=0.25 I_{x x}$

Maximum roll angular velocity is: 
$\omega_{x}==\frac{2 \pi \theta_{m}}{T_{0}}$

In the formula, $T_{0}$ is for the rolling period.

The maximum roll energy of the tug is:

$U_{\max }=\frac{1}{2} I_{x} \omega_{x}^{2}$

In the formula: $I_{x} \longrightarrow$ Sum of roll moment and the inertia moment;

$I_{x}=I_{x x}+J_{x x}$

In the drag operation, at least three rubber fenders under the water will contact with the ship and have compressive deformation. The counter force of each rubber fender in compressive deformation is up to $441.5 \mathrm{KN}$, the absorbed energy is about $23.7 \mathrm{KJ}$.The total counter force is about $1324.5 \mathrm{KN}$, the total absorbed energy is about $71.1 \mathrm{KJ}$. Therefore, when the tug roll equals $8^{\circ}$, the rubber fender can withstand the impact of rolling kinetic energy.

The pushing inertia moment in the hydrostatic is[5]:

$\mathrm{I}_{y y}=0.07 C_{w} \frac{D}{g} L^{2}$

In the formula, $C_{w}$ - - Waterplane coefficient;

$D$ - The water displacement of ships;

$g$ - - The acceleration of gravity;

$L$ - The length of the ship.

Pitching inertia moment:

$J_{y y}=I_{y y}$

The period of pitch is:

$T_{0}^{\prime}=2.8 \sqrt{C_{V P} d}$

$C_{V P}$ - Vertical prismatic coefficient, $C_{V P}=\frac{C_{B}}{C_{w}}$;

$d$ - - Ship waterline.

The maximum longitudinal angular velocity is:

$\omega_{y}=\frac{2 \pi \varphi_{m}}{T_{0}^{\prime}}$

The maximum pitching kinetic energy is:

$U_{\max }^{\prime}=\frac{1}{2} I_{y} \omega_{y}^{2}$

In the formula:

$I_{y}$ - - Sum of rolling and Pitching inertia moment.

$I_{y}=I_{y y}+J_{y y}$

In the pushing operation, the rubber fender at the stem will contact with the ship and have compressive deformation. According to the deformation,the counter force of the fender is about $222.2 \mathrm{KN}$, The absorbed energy is about $24.2 \mathrm{KJ}$.It proves that the fender can bear the impact of pitching kinetic energy.

\section{The Influence on the center of gravity}

Arranging the rubber fenderis symmetrically is favorable to reduce the influence of the center of gravity.In order to compare the values in two cases,we calculate the center of gravity with the Tribon software. 
The center of gravity without the rubber fenderis is:

$$
x_{1}: 13987 ; Y_{1}: 2 ; Z_{1}: 2695 ; W_{t 1}: 128926 \mathrm{~kg} \text {; }
$$

The center of gravity with the rubber fenderis is:

$x_{2}: 14295 ; Y_{2}: 2 ; Z_{2}: 2858 ; W_{t 2}: 150556 \mathrm{~kg}$;

By comparision,the increment is:

$x_{2}-x_{1}=308 ; Y_{2}-Y_{1}=2$;

$Z_{2}-Z_{1}=163 ; W_{t 2}-W_{t 1}=21630 \mathrm{Kg}$

If we consider the center of gravity of the whole ship, the rubber fender has a less effect on the center of gravity.The total weight of the rubber fender is about 21.63t.It can meet the requirements,less than 25t.It ensures that the ship has enough margin and meet the various requirements of the working conditions.

\section{The calculation and simulation the of viscous resistance}

We establish the model of the tug to estimate the resistance with GAMBIT software. In order to reduce the mesh and ensure the effective simulation of the boundary layer on the surface of the hull,we decrease the principal dimensions by $1 / 10$.The wet surface area $S=3.5453 \mathrm{~m}^{2}$. The model of the surface is shown as Fig1.

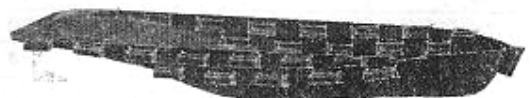

Fig.1. The model of the surface

The differential equation of the viscous fluid motion is solved by FLUENT software with S-A turbulence model.Fig.2 shows the diagram of the vicous coefficient.The abscissa is the Reynolds number $R_{e}$, the ordinate is the viscous coefficient $C_{d}$.

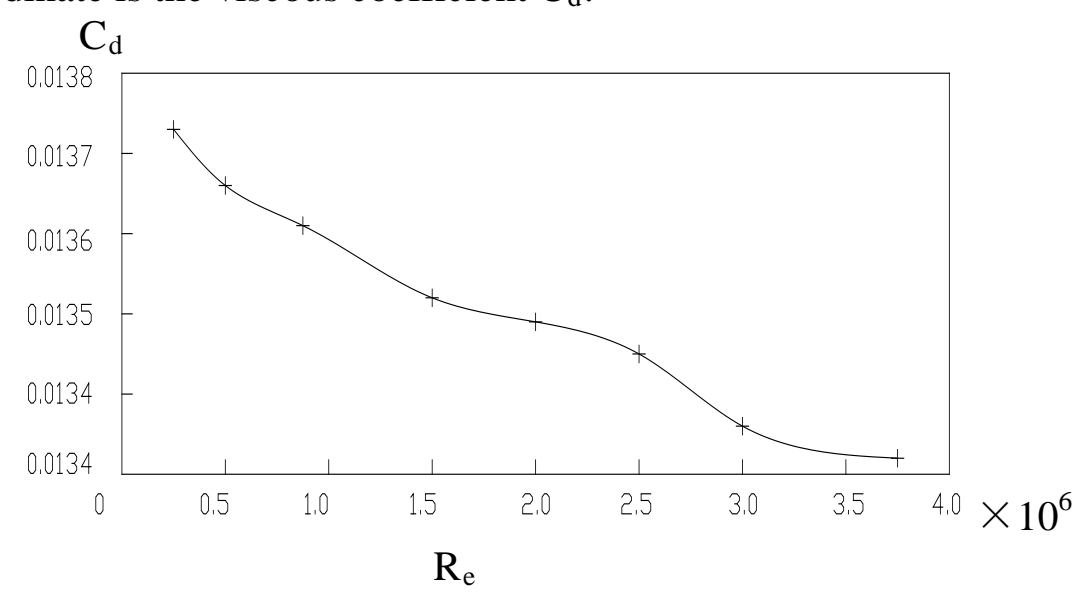

Fig.2. The viscous coefficient

Table 1 gives the viscous with the Re in two cases. Table 2.shows that the prediction speed Vs is not less than $11.5 \mathrm{kn}$ after considering the wave resistance and air resistance.

Table1.The viscous with the Re number in two cases

\begin{tabular}{cccc}
\hline Number & $\mathrm{R}_{\mathrm{e}} \times 10^{6}$ & $\begin{array}{c}\mathrm{C}_{\mathrm{d}} \times 10^{3} \\
\text { (no fender) }\end{array}$ & $\begin{array}{c}\mathrm{C}_{\mathrm{d}} \times 10^{3} \\
\text { (with fender) }\end{array}$ \\
\hline 1 & 2.5 & 9.50 & 13.73 \\
2 & 5.0 & 8.43 & 13.66 \\
3 & 8.75 & 7.76 & 13.61 \\
4 & 15.0 & 7.24 & 13.52 \\
5 & 20.0 & 7.01 & 13.49 \\
6 & 25.0 & 6.84 & 13.45 \\
7 & 30.0 & 6.71 & 13.36 \\
8 & 37.5 & 6.57 & 13.32 \\
\hline
\end{tabular}


The viscous resistance of the ship is: $R_{v}=C_{d} \times \frac{1}{2} \rho V^{2} s$. The value of the calculation is shown as Table2.

Table 2.The viscous resistance

\begin{tabular}{cccc}
\hline Number & $\mathrm{V}(\mathrm{kn})$ & $\mathrm{V}(\mathrm{m} / \mathrm{s})$ & $\mathrm{R}(\mathrm{kN})$ \\
\hline 1 & 7 & 3.60 & 30.64 \\
2 & 8 & 4.12 & 40.14 \\
3 & 9 & 4.63 & 50.68 \\
4 & 10 & 5.14 & 62.46 \\
5 & 11 & 5.66 & 75.73 \\
6 & 12 & 6.17 & 89.99 \\
7 & 13 & 6.69 & 105.80 \\
8 & 14 & 7.20 & 122.55 \\
\hline
\end{tabular}

\section{Conclusion}

The quantitative design and calculation based on Tribon are finished with no clear specification requirement and calculation method about HP2000. By the calculation and analysis of the viscous resistance of the wet surface,It proves that the methord of underwater rubber fender can not only satisfy the use requirement, but also make the center of gravity, ship sailing resistance and speed satisfy the requirements of expectations.

\section{References}

[1] Bairan Li.Performance Requirement and Development Trend of Harbor Tugboats[J]. logistics technology,2010,8,135-136.

[2] Hua Yang,The Configuration of Pilot Boat and Its Effectiveness Assessment[J]. Ship \& Ocean Engineering, 2010,39 (5),40-42.

[3] Yadong Yang,Wei Wang .Discussion on the Power of Tugs for Large Tankers Going in and out of Qingzhou Port[J]. Ship \& Ocean Engineering.2012,4,135-138.

[4] Tianying Wang.Yongxun Feng. Advanced Development of Research on New Concept FPSOs[J]. Ship \& Ocean Engineering, 2011,40 (5): 184-188.

[5] Xiaoming Pan,Principle of Ship [M]. People trafficpress, Beijing,2007 